\title{
Inhalation Administration of the Sesquiterpenoid Aristolen-1(10)-en-9-ol from Nardostachys chinensis Has a Sedative Effect via the GABAergic System
}

Authors

Affiliations
Hiroaki Takemoto ${ }^{1}$, Michiho Ito $^{2}$, Yoshihisa Asada ${ }^{3}$, Yoshinori Kobayashi ${ }^{1}$

${ }^{1}$ School of Pharmacy, Kitasato University, Tokyo, Japan

${ }^{2}$ Graduate School of Pharmaceutical Sciences, Kyoto University, Kyoto, Japan

${ }^{3}$ Faculty of Pharmaceutical Sciences, Tokyo University of Science, Tokyo, Japan
Key words

- Nardostachys chinensis

- Valerianaceae

- aristolen-1(10)-en-9-ol

- inhalation administration

- sedation

- GABAergic system received October 10, 2014 revised January 27, 2015 accepted January 29, 2015

Bibliography

DOI http://dx.doi.org/

10.1055/s-0035-1545725

Published online March 23,

2015

Planta Med 2015; 81: 343-347

(c) Georg Thieme Verlag KG

Stuttgart · New York .

ISSN 0032-0943

Correspondence

Dr. Michiho Ito

Department of Pharmacognosy

Graduate School of

Pharmaceutical Sciences

Kyoto University

46-29 Yoshida

Shimoadachi, Sakyo-ku,

Kyoto 606-8501

Japan

Phone: +81757534506

Fax: +81757534507

michihoi@pharm.kyoto-u.ac.jp

\section{Abstract}

$\nabla$

Spikenard, the dried roots of Nardostachys chinensis, contains sesquiterpenoids and is widely used as an herbal tranquilizer. We previously demonstrated that spikenard vapor showed a sedative effect when administered by inhalation, and we identified hydrocarbon sesquiterpenoids as active components. Here we investigated the other components that contribute to the effects of spikenard. Six oxygenated sesquiterpenoids, including aristolane- and guaiane-types, were isolated from an acetone extract of spikenard. We evaluated the sedative activities of these oxygenated compounds using an inhalation administration method in a caffeine-treated excitatory mouse model. We identified aristolen-1(10)-en9-ol and patchouli alcohol as highly effective sedative components. These compounds inhibited locomotion in mice by approximately $60 \%$ at a dose

\section{Introduction}

\section{$\nabla$}

Various stress conditions in daily life influence human health and may cause physical disorders, such as insomnia [1] and anxiety [2]. Benzodiazepines are widely used as sedative drugs but are associated with problematic side effects, including oversedation [3] or ataxia [4]. Therefore, as one of the complementary and alternative medicinal therapies, aromatherapy has recently attracted much attention for its ability to induce relaxation and to ameliorate stress. Spikenard, the dried underground part of Nardostachys chinensis Batalin, is a member of the family Valerianaceae found growing from Himalayan regions to southwest China. In traditional Chinese medicine, spikenard has been used as a gastrointestinal antispasmodic [5] and a traditional herbal tranquilizer [6]. Spikenard is also an essential ingredient in scented sachets used to improve insomnia. of $300 \mu \mathrm{g} /$ cage. In addition, aristolen-1(10)-en-9ol prolonged pentobarbital-induced sleep to the same extent as $1 \mathrm{mg} / \mathrm{kg}$ diazepam. This effect completely disappeared with the administration of the $\mathrm{GABA}_{\mathrm{A}}$-benzodiazepine receptor antagonist flumazenil $(3 \mathrm{mg} / \mathrm{kg})$, suggesting that the sedative effect of aristolen-1(10)-en-9-ol is expressed via the GABAergic system. Furthermore, differently from diazepam, inhalation of aristolen-1(10)-en-9-ol for $1 \mathrm{~h}$ did not affect the motor coordination in the rota-rod test. In the present study, we identified active components and provided evidence supporting the traditional sedative use of spikenard. Our research suggests that aristolen-1(10)-en-9-ol may be an effective aromatherapy, providing mild sedation.

Supporting information available online at http://www.thieme-connect.de/products

Our research focused on the characteristic fragrance of spikenard, the expression of the sedative effect by fragrance inhalation, and the identification of active ingredients. In our previous study, we investigated the sedative effect of the spikenard hexane extract by inhalation administration in mice. We identified four hydrocarbon sesquiterpenoids from the spikenard hexane extract as active compounds $[7,8]$ and also revealed that its sedative effect due to administration by inhalation was expressed via olfactory stimulation and pulmonary absorption [9]. While preparing the spikenard essential oil to identify other volatile compounds by GC-MS analysis, we detected several high intensity peaks in addition to the peaks for hydrocarbon sesquiterpenoids mentioned above ( $\bullet$ Fig. 1 ). The aim of the present study was to identify those compounds and to determine whether they contribute to the sedative effect of spikenard. The sedative activities of iso- 


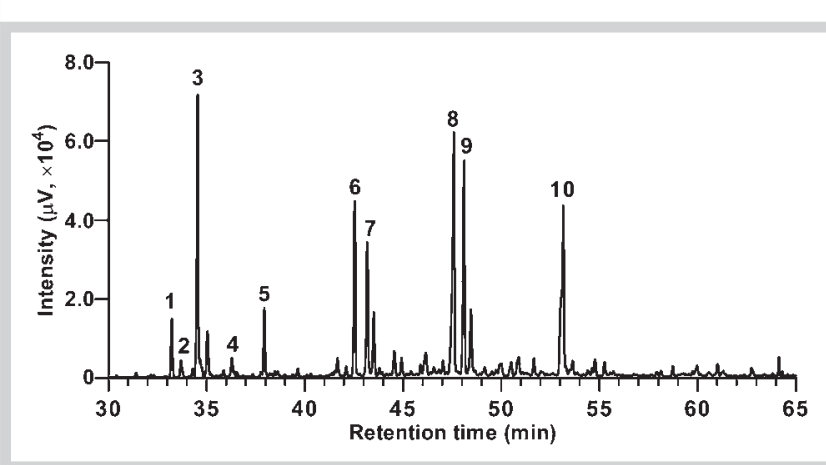

Fig. 1 A GC chromatogram of the GC-FID analysis of the spikenard oil. The retention index (RI) and percent of composition of the ten main peaks are indicated below. 1: $\beta$-maaliene, RI 1405, 3.1\%; 2: aristolene, RI 1413, $2.1 \%$; 3: calarene, RI 1428, $13.5 \%$; 4: valerena-4,7(11)-diene, RI 1459, 1.9\%; 5 : $\beta$ ionone, RI 1485, 3.6\%; 6: maaliol, RI 1562, 6.4\%; 7: spathulenol, RI 1573, 5.6\%; 8: patchouli alcohol, RI 1650, 11.6\%; 9: aristolen-1(10)-en-9-ol, RI 1661, 13.6\%; and 10: 1(10)-aristolen-2-one, RI 1754, 4.4\%.

lated compounds were evaluated in a caffeine-treated excitatory mouse model, using an inhalation administration method and an open-field test. The locomotor activity of these mice was more than doubled by caffeine administration [8]; therefore, the sedative activity of each compound could be easily detected. We also investigated the mechanism of the sedative action of the highly active compounds. To examine the involvement of the GABAergic system, we performed a pentobarbital sleep test with a $\mathrm{GABA}_{\mathrm{A}^{-}}$ benzodiazepine receptor antagonist, flumazenil. We describe the characteristic compounds contained in spikenard and involved in its sedative effect.

\section{Results}

$\nabla$

Six oxygenated sesquiterpenoids were isolated from the spikenard acetone extract in this study. O Fig. 1 shows the GC-FID chromatogram of the spikenard oil, and the calculated retention index and content ratio of each compound identified in the spikenard oil in the present study are indicated. Fig. 2 shows the chemical structures of these compounds, of which six compounds were aristolane-type and two compounds were guaiane-type. Aristolen-1(10)-en-9-ol (13.6\%) and patchouli alcohol (11.6\%) were the main components of the spikenard oil, in addition to the volatile hydrocarbon calarene (13.5\%). The sedative effects of the six oxygenated compounds were evaluated. To investigate whether the isolated oxygenated sesquiterpenoids contribute to the effect of spikenard, we assessed the total spontaneous locomotor activity of caffeine-treated mice in an openfield test. Fig. 3 shows the total motor activity of mice exposed to various concentrations of sample solutions for $60 \mathrm{~min}$. Diazepam, a positive control, inhibited the increase in locomotor activity of caffeine-treated mice dose-dependently, and the inhibition ratios at doses of 1 and $5 \mathrm{mg} / \mathrm{kg}$ were 60 and $80 \%$, respectively. Inhalation of the spikenard oil significantly sedated the caffeinetreated mice at a dose of $300 \mu \mathrm{g} /$ cage (inhibition ratio, $41 \%$ ). Of the isolated compounds, maaliol and $\beta$-ionone tended to show a sedative effect but not significantly. In contrast, both 1(10)-aristolen-2-one and spathulenol showed significant sedative activity at a dose of $300 \mu \mathrm{g} /$ cage, with the inhibition ratios of 34 and $53 \%$, respectively. Patchouli alcohol and aristolen-1(10)-en-9-ol had dose-dependent sedative effects, and the inhibition ratios at a dose of $300 \mu \mathrm{g} /$ cage were 69 and $63 \%$, respectively, and these effects were comparable to $1 \mathrm{mg} / \mathrm{kg}$ diazepam.

The involvement of the GABAergic system in the sedative effects of patchouli alcohol and aristolen-1(10)-en-9-ol was investigated using a pentobarbital sleep test ( Fig. 4). Orally administered diazepam prolonged pentobarbital-induced sleeping times in a dose-dependent manner. Compared with the vehicle alone, diazepam significantly prolonged sleep duration at 1 and $5 \mathrm{mg} / \mathrm{kg}$ by $44 \mathrm{~min}$ (64\% prolongation) and $107 \mathrm{~min}$ (299\% prolongation), respectively. No effect was observed in the patchouli alcohol inhalation group; however, inhalation of aristolen-1(10)-en-9-ol (300 $\mu \mathrm{g} / \mathrm{cage}$ ) significantly prolonged the sleeping time (47 min, $84 \%$ prolongation), and this effect was comparable to $1 \mathrm{mg} / \mathrm{kg}$ diazepam. To investigate the involvement of the GABAergic system, the mice were pretreated with flumazenil, a specific $G_{A B A}$-benzodiazepine antagonist ( Fig.5). Pretreatment with flumazenil alone did not affect pentobarbital-induced sleep duration, but the hypnotic activity of $1 \mathrm{mg} / \mathrm{kg}$ diazepam was inhibited by pretreatment with $3 \mathrm{mg} / \mathrm{kg}$ flumazenil. In addition, the hypnotic effect of aristolen-1(10)-en-9-ol was completely antagonized by flumazenil.

The influence of drug administration on the motor function was investigated using a rota-rod test for $5 \mathrm{~min}$. Fig. 6 shows the endurance time (time to fall) of mice treated with diazepam or aristolen-1(10)-en-9-ol. In the diazepam group, a dose of $0.2 \mathrm{mg} / \mathrm{kg}$ did not disturb the motor coordination. However, doses of 1 and $5 \mathrm{mg} / \mathrm{kg}$ disturbed the motor coordination in a dose-dependent manner, with mean endurance times of 195 and $37 \mathrm{sec}$, respec-

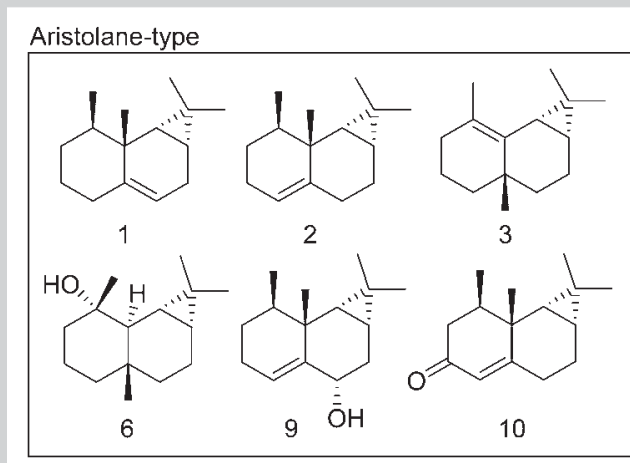

\section{Guaiane-type}

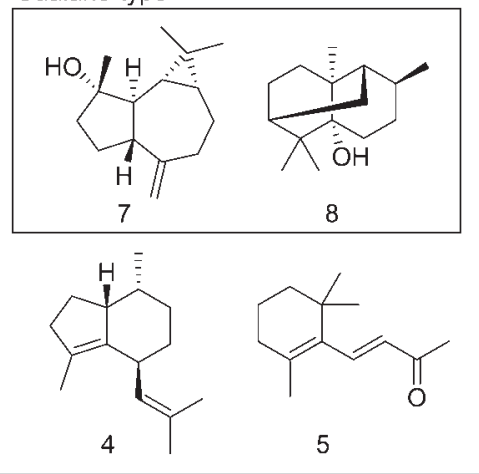

Fig. 2 Chemical structures of sesquiterpenoids as numbered in the GC chromatogram in 0 Fig. 1. 


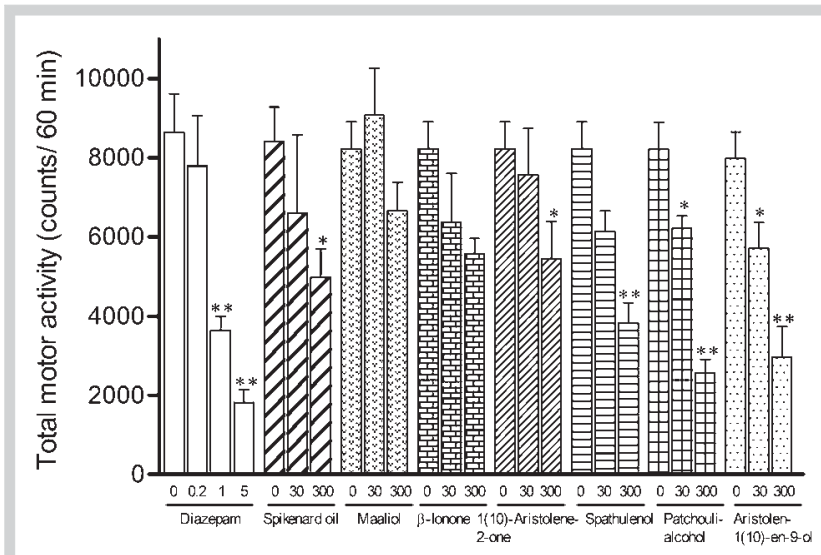

Fig. 3 Total motor activity of caffeine-treated mice exposed to the vapor of oxidized sesquiterpenoids ( 0,30 , and $300 \mu \mathrm{g} /$ cage). Results represent mean \pm SD of values for each group $(n=8) .{ }^{*} P<0.05,{ }^{* *} p<0.01$ vs. vehicle group; one-way ANOVA followed by Tukey's test.

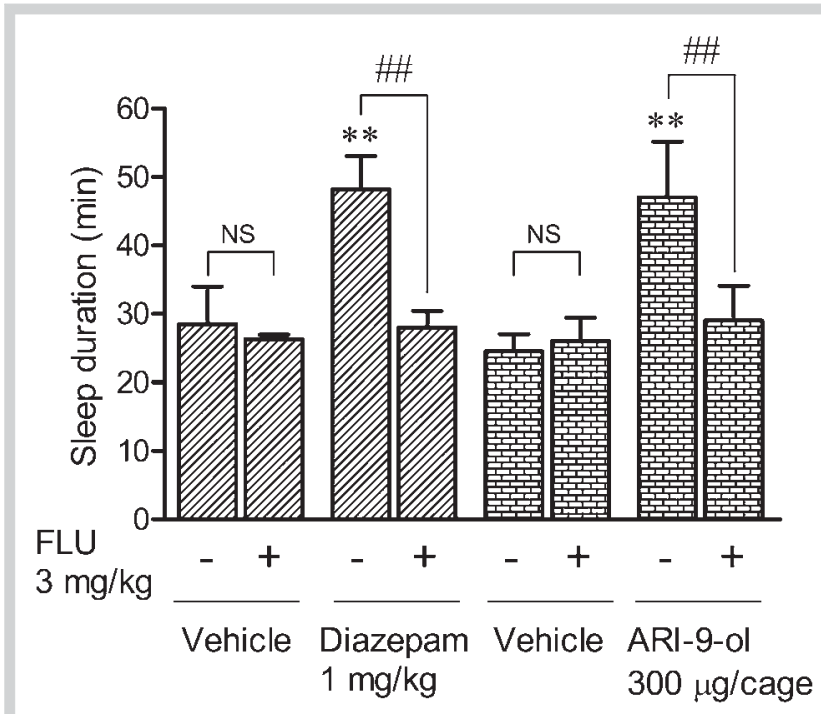

Fig. 5 Effect of flumazenil (FLU) on sleep duration in mice treated with diazepam (po) and aristolen-1(10)-en-9-ol (ARI-9-ol) (inhalation). Results represent mean $\pm S D$ of values for each group $(n=8)$. ${ }^{* *} P<0.01$ vs. vehicle group (Student's t-test), ${ }^{\# \#} \mathrm{p}<0.01$ for FLU treatment vs. treatment without FLU (Student's t-test). NS, not significant.

tively. Half (4/8) of the mice in the $1 \mathrm{mg} / \mathrm{kg}$ diazepam group and all $(8 / 8)$ of the mice in the $5 \mathrm{mg} / \mathrm{kg}$ group fell from the rod. Aristolen1(10)-en-9-ol inhalation for $1 \mathrm{~h}$ did not affect the motor coordination in the rota-rod test.

\section{Discussion}

$\nabla$

Spikenard has been widely used as a traditional herbal tranquilizer and in scented sachets to improve insomnia. Given that inhalation is a noninvasive administration route, we investigated the sedative effect of volatile compounds to assess the effectiveness

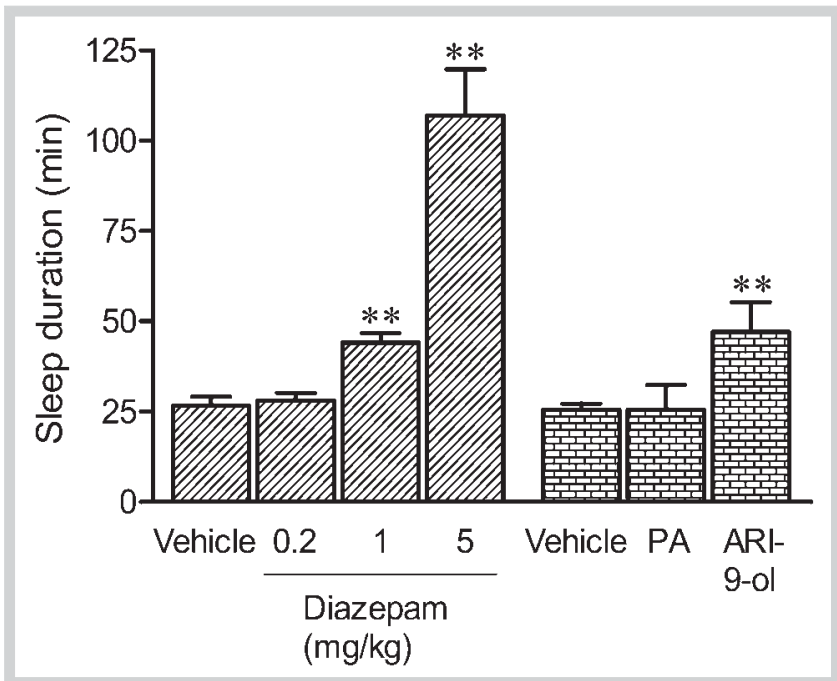

Fig. 4 Effects of vaporized patchouli alcohol (PA) and aristolen-1(10)-en9-ol (ARI-9-ol) on sleep duration in a pentobarbital sleep test. Results represent mean $\pm S D$ of values for each group $(n=8)$. ${ }^{*} P<0.01$ vs. vehicle group; one-way ANOVA followed by Tukey's test.

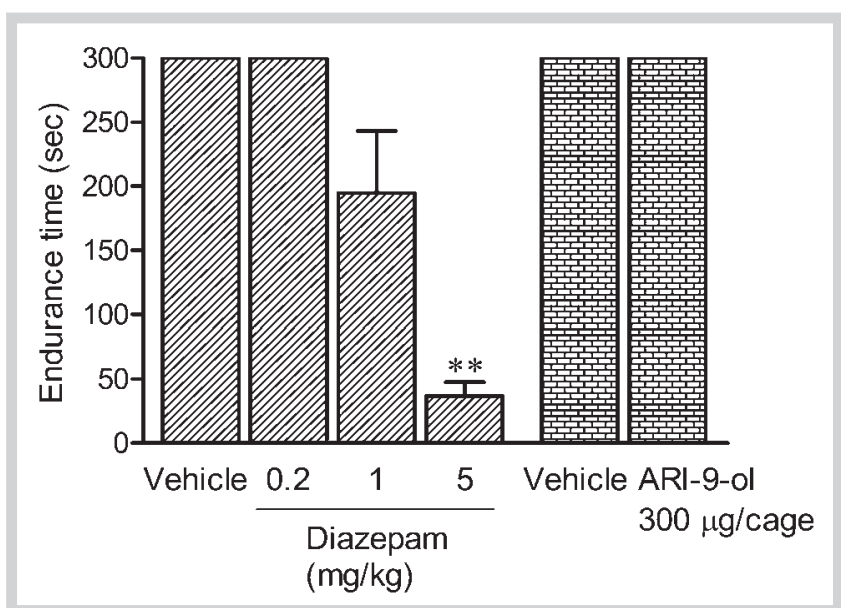

Fig. 6 Effect of aristolen-1(10)-en-9-ol (ARI-9-ol) on the rotating rod performance of mice. Each bar represents mean \pm SD of the endurance time during the 5 min rota-rod test $(n=8)$. ${ }^{* *} P<0.01$ vs. vehicle group; one-way ANOVA followed by Tukey's test.

of spikenard as aromatherapy. On GC analysis of the spikenard oil, we identified several high-intensity peaks in addition to the peaks for the hydrocarbon sesquiterpenoids identified previously. These compounds were identified as oxidized sesquiterpenoids, including aristolane- and guaiane-type compounds. Openfield testing of caffeine-treated mice exposed to aristolen-1(10)en-9-ol and patchouli alcohol demonstrated that these compounds have high sedative activity when administered by inhalation. In the pentobarbital-sleep test, to investigate the involvement of the GABAergic system, aristolen-1(10)-en-9-ol significantly prolonged the sleeping duration. Because we could not find an appropriate positive control drug with a known pharmacological mechanism using the same inhalation administration route, we used diazepam as a positive control. The administration of $5 \mathrm{mg} / \mathrm{kg}$ diazepam prolonged the sleeping duration by 
$299 \%$ and markedly impaired the motor coordination, which is a well-known undesirable side effect of diazepam. Therefore, $5 \mathrm{mg} /$ $\mathrm{kg}$ diazepam was strongly sedative. Diazepam ( $1 \mathrm{mg} / \mathrm{kg}$ ) also prolonged the sleeping duration and mildly impaired the motor coordination. Therefore, $1 \mathrm{mg} / \mathrm{kg}$ diazepam was mildly sedative. The effect of aristolen-1(10)-en-9-ol was comparable to that of $1 \mathrm{mg} / \mathrm{kg}$ diazepam and was completely inhibited by $3 \mathrm{mg} / \mathrm{kg}$ flumazenil. Therefore, the sedative effect of aristolen-1(10)-en-9-ol appeared to involve agonism of the $\mathrm{GABA}_{\mathrm{A}}$-benzodiazepine receptor. Rota-rod testing demonstrated that aristolen-1(10)-en9-ol induced relaxation without the motor impairment or marked sedation. The sedative effect of patchouli alcohol appears to be mediated by a system other than the GABAergic system.

A previous study found that the essential oil of Valeriana wallichi, which contains patchouli alcohol (40.2\%), has an antidepressant effect [10]. Furthermore, administration of $V$. wallichi essential oil increased cerebral serotonin and norepinephrine levels to a similar extent as imipramine. Imipramine also has a sedative effect; therefore, the mechanism of action of patchouli alcohol could involve the cerebral monoamine system. However, further research is needed to confirm this possible mechanism. In the present study, we identified active components of spikenard and provided evidence supporting the traditional sedative use of this compound. Although more studies are required to further elucidate the properties of aristolen-1(10)-en-9-ol, our research suggests that aristolen-1(10)-en-9-ol may be an effective aromatherapy, providing mild sedation.

\section{Materials and Methods}

$\nabla$

General

Triethyl citrate (purity > 99\%, GC; Wako Pure Chemical Industries, Ltd.), an odorless solvent, was used to dissolve the isolated compounds or the spikenard oil. Caffeine (purity $>98.5 \%$, TLC) and diazepam (purity $>98 \%$, Ti) were purchased from Wako Pure Chemical Industries, Ltd., flumazenil (purity >99\%, HPLC) was obtained from Sigma-Aldrich, Inc., and pentobarbital sodium salt (purity $>98 \%$, N) was obtained from Tokyo Chemical Industry Co., Ltd. Caffeine and pentobarbital were dissolved in physiological saline, and diazepam and flumazenil were suspended in a solution of dimethyl sulfoxide: Tween-80:physiological saline $=$ $1: 1: 8$. Column chromatography was performed using $60 \mathrm{~N}$ silica gel (40-50 $\mu \mathrm{m}$, Kanto Chemical Co., Ltd.) and Cosmosil ${ }^{\circledR} 75 \mathrm{C}_{18^{-}}$ PREP (Nacalai Tesque, Inc.). Preparative HPLC was performed using Cosmosil ${ }^{\circledR} 5 \mathrm{C}_{18}$-AR-2 (150 mm $\times 20 \mathrm{~mm}$ ID), and the compounds were detected using UV (SPD-10A; Shimadzu Corporation) and a refractive index (RI-72, Showa Denko K.K.) detector. All chemicals and reagents were of the highest grade.

\section{Plant material}

Spikenard (lot number: 0080) was purchased from Mitsuboshi Pharmaceutical Co., Ltd. and identified by the authors. A voucher specimen of the plant material (No.3735) was deposited in the Herbarium of Medicinal Plants Garden, Tokyo Metropolitan Institute of Public Health.

\section{Preparation of the essential oil}

Spikenard oil was isolated from the dried plant material by hydrodistillation for $3 \mathrm{~h}$ using a Clevenger-type apparatus according to previously reported methods [11].

\section{GC-FID and GC-MS analysis}

Quantitative analysis of the volatile component: GC-FID analyses were performed on a GC-2014 (Shimadzu Corporation) with a flame ionization detector, and operating conditions were as follows: Column, Rtx ${ }^{\circledR}-5 \mathrm{MS}$ (Restek Corporation), $30 \mathrm{~m} \times 0.25 \mathrm{~mm}$, $0.25 \mu \mathrm{m}$ film thickness; column temperature, $60^{\circ} \mathrm{C}(1 \mathrm{~min}$ hold $)=180^{\circ} \mathrm{C}\left(\Delta 2^{\circ} \mathrm{C} / \mathrm{min}\right)=280^{\circ} \mathrm{C}\left(\Delta 10^{\circ} \mathrm{C} / \mathrm{min}, 15 \mathrm{~min}\right.$ hold $)$; carrier gas, helium $(39.2 \mathrm{~cm} / \mathrm{s})$; injector, $230^{\circ} \mathrm{C}$; detector, $300^{\circ} \mathrm{C}$; injection volume, $1 \mu \mathrm{L}$ (splitless).

Qualitative analysis of the volatile component: GC-MS analyses were performed on a GC-2010/GCMS-QP2010 Plus (Shimadzu Corporation), with operating conditions as follows: column and column temperature as above; carrier gas, helium $(38.3 \mathrm{~cm} / \mathrm{s})$; injector, $230^{\circ} \mathrm{C}$; interface, $250^{\circ} \mathrm{C}$; ion source, $200^{\circ} \mathrm{C}$; injection volume, $1 \mu \mathrm{L}$ (splitless). MS was operated in the EI mode at an ionization voltage of $70 \mathrm{eV}$ over an $\mathrm{m} / \mathrm{z}$ range from 30 to $400 \mathrm{amu}$. Retention indices were determined relative to the retention times of a series of $n$-alkane standards (10-20 carbons; GL Sciences, Inc.), measured under the chromatographic conditions described above.

\section{Extraction and isolation}

Spikenard (150g) was subjected to acetone extraction three times at room temperature. The acetone extract was concentrated under reduced pressure and silica gel column chromatography $(25 \times 5 \mathrm{~cm})$ was performed using the concentrate $(12 \mathrm{~g})$. The column was first eluted with $n$-hexane to yield fractions 15 , and then eluted with $n$-hexane-EtOAc mixtures with increasing polarity ( $40: 1$ to $2: 1$ ) to yield fractions $6-12$. Fraction 7 (159.3 mg) was purified by preparative HPLC [solvent, $\mathrm{CH}_{3} \mathrm{CN}: \mathrm{H}_{2} \mathrm{O}$ (70:30); flow rate, $\left.6.0 \mathrm{~mL} / \mathrm{min}\right]$, which yielded $\beta$ ionone $(5.66 \mathrm{mg})$. Fraction $8(268.5 \mathrm{mg})$ was applied to an ODS column $(14 \times 2.6 \mathrm{~cm})$ and eluted with $\mathrm{CH}_{3} \mathrm{CN}: \mathrm{H}_{2} \mathrm{O}(6: 4$ to $10: 0)$ to yield fractions $1-5$, while further preparative HPLC of the fraction 8-3 (177.2 mg) [solvent, $\mathrm{CH}_{3} \mathrm{CN}: \mathrm{H}_{2} \mathrm{O}$ (82:18); flow rate, $6.0 \mathrm{~mL} / \mathrm{min}$ ] yielded patchouli alcohol (154.3 mg). Fraction 10 (978.3 $\mathrm{mg}$ ) was chromatographed over ODS using the same conditions described above. Seven fractions were obtained, and further preparative HPLC of fraction $10-2$ [734.7 mg; solvent, $\mathrm{CH}_{3} \mathrm{CN}: \mathrm{H}_{2} \mathrm{O}$ (70:30); flow rate, $6.0 \mathrm{~mL} / \mathrm{min}$ ] yielded $1(10)$-aristolen-2-one (62.8 mg) as fraction 10-2-1. Fraction 10-2-2 was further purified by preparative $\mathrm{HPLC}$ [solvent, $\mathrm{CH}_{3} \mathrm{CN}: \mathrm{H}_{2} \mathrm{O}$ (73:27); flow rate, $6.0 \mathrm{~mL} / \mathrm{min}$ ] to yield spathulenol $(60.5 \mathrm{mg})$, aristolen-1(10)-en-9-ol (244.3 mg), and maaliol (78.2 mg). The purities of isolated compounds were over $98 \%$ (GC-FID).

\section{Animals}

Four-week-old male ddY mice were purchased from Japan SLC, Inc. Prior to experimentation, the mice were acclimatized for one week to a temperature of $25^{\circ} \mathrm{C} \pm 2{ }^{\circ} \mathrm{C}$, humidity of $50 \% \pm$ $10 \%$, and a 12-h light/12-h dark cycle. All behavioral observations were recorded between 10:00 and 15:00 h. Experiments were performed in accordance with the Kitasato University guidelines for animal care, handling, and termination, which are in line with the international and Japanese guidelines for animal care and welfare (approval number: FR07-2, date: May 1, 2013).

\section{Inhalation administration}

The fragrance components were dissolved in triethyl citrate $(30 \mu \mathrm{L}$ total) for the experiments. A thick paper disk $(2.5 \times$ $3.0 \mathrm{~cm}, 1 \mathrm{~mm}$ in thickness) was permeated with sample solution and placed on a hotplate diffuser (approximately $70^{\circ} \mathrm{C}$ ) in the 
upper portion of the cage. The cylindrical cage was made of transparent polycarbonate ( $22 \mathrm{~cm}$ in height, $25 \mathrm{~cm}$ in diameter) and covered with vinyl film so the vapor from the sample solution could pervade the cage. A mouse treated with caffeine or pentobarbital was placed in the center of the cage $30 \mathrm{~min}$ after charging the solution. The fragrance inhalation dose was set to 30 or $300 \mu \mathrm{g} /$ cage, on the basis of previous studies [7].

\section{Caffeine administration test}

Caffeine was orally administered to mice at a dose of $20 \mathrm{mg} / \mathrm{kg}$. Each mouse was placed in a cage filled with vapor from the sample solution $30 \mathrm{~min}$ after administration, and the locomotor activity was measured for another 60 min using an open-field test. As a positive control, diazepam was administered at doses of 0.2 , 1 , and $5 \mathrm{mg} / \mathrm{kg}$ (po) $30 \mathrm{~min}$ before caffeine peroral administration. The test was performed according to the method described by Kobayashi et al. [12] in the same cylindrical cages equipped with a passive infrared sensor (PYS-001; Muromachi Kikai Co., Ltd.). Spontaneous motor activity was recorded using a passive infrared sensor detection system (Supermex; Muromachi Kikai Co., Ltd.) and analyzed using CompACT AMS software (Muromachi Kikai Co., Ltd.).

\section{Pentobarbital sleep test}

Mice were administered pentobarbital (ip) at a dose of $30 \mathrm{mg} / \mathrm{kg}$ and immediately placed in a cage filled with vapor of the sample solution $(300 \mu \mathrm{g} /$ cage $)$. Sleep duration was defined as the time difference between loss and recovery of the righting reflex. As a positive control, diazepam at a dose of $0.2,1$, and $5 \mathrm{mg} / \mathrm{kg}$ (po) was administered $30 \mathrm{~min}$ before pentobarbital injection. Flumazenil, a specific $G_{A B A}$-benzodiazepine receptor antagonist, was administered ( $3 \mathrm{mg} / \mathrm{kg}$, ip) $60 \mathrm{~min}$ prior to pentobarbital injection.

\section{Rota-rod test}

A rota-rod treadmill (MK-600; Muromachi Kikai Co., Ltd) was used in this study. To adapt to the rota-rod, one day before the test, mice were placed on the rod rotating at $28 \mathrm{rpm}$ for $5 \mathrm{~min}$ each hour three times. On the test day, one more episode of training was performed, and the mice that failed to stay on the rod were excluded from the experiment. The duration, up to $5 \mathrm{~min}$, that mice could remain on the rota-rod was recorded after $60 \mathrm{~min}$ of sample inhalation or $30 \mathrm{~min}$ after diazepam administration.

\section{Statistical analysis}

All results are expressed as the mean \pm standard deviation (SD). The data were analyzed using one-way analysis of variance (ANOVA) followed by Tukey's multiple comparison test. For the flu- mazenil treatment experiment ( Fig.5), Student's t-test was used to compare the values from the two groups. All statistical analyses were performed using Prism 5 (GraphPad Software, Inc.), and $\mathrm{p}$ values $<0.05$ were considered to be significant.

\section{Supporting information}

Spectral data for the isolated compounds are available as Supporting Information.

\section{Conflict of Interest \\ $\nabla$}

The authors declare no conflict of interest.

\section{References}

1 Meerlo P, Sgoifo A, Suchecki D. Restricted and disrupted sleep: effects on autonomic function, neuroendocrine stress systems and stress responsivity. Sleep Med Rev 2008; 12: 197-210

2 Leuner B, Shors TJ. Stress, anxiety, and dendritic spines: what are the connections? Neuroscience 2013; 251: 108-119

3 Loeffler PM. Oral benzodiazepines and conscious sedation: a review. J Oral Maxillofac Surg 1992; 50: 989-997

4 Licata SC, Platt DM, CookJM, Van Linn ML, Rowlett JK. Contribution of $\alpha 1$ subunit-containing $\gamma$-aminobutyric $\operatorname{acid}_{A}\left(G_{A B A}\right)$ receptors to motorimpairing effects of benzodiazepines in squirrel monkeys. Psychopharmacology 2009; 203: 539-546

5 Tanaka K, Komatsu K. Comparative study on volatile components of Nardostachys Rhizome. J Nat Med 2008; 62: 112-116

6 Zhang Y, Lu Y, Zhang L, Zheng QT, Xu LZ, Yang SL. Terpenoids from the roots and rhizomes of Nardostachys chinensis. J Nat Prod 2005; 68: 1131-1133

7 Takemoto H, Ito M, Shiraki T, Yagura T, Honda G. Sedative effects of vapor inhalation of agarwood oil and spikenard extract and identification of their active components. J Nat Med 2008; 62: 41-46

8 Takemoto H, Yagura T, Ito M. Evaluation of volatile components from spikenard: valerena-4, 7(11)-diene is a highly active sedative compound. J Nat Med 2009; 63: 380-385

9 Takemoto H, Omameuda Y, Ito M, Fukuda T, Kaneko S, Akaike A, Kobayashi $Y$. Inhalation administration of valerena-4,7(11)-diene from Nardostachys chinensis roots ameliorates restraint-induced changes in murine behavior and stress-related factors. Biol Pharm Bull 2014; 37: 1050-1055

10 Sah SP, Mathela CS, Chopra K. Involvement of nitric oxide (NO) signaling pathway in the antidepressant activity of essential oil of Valeriana wallichii Patchouli alcohol chemotype. Phytomedicine 2011; 18: 1269-1275

11 Ito $K$, Ito $M$. Sedative effects of vapor inhalation of the essential oil of Microtoena patchoulii and its related compounds. J Nat Med 2011; 65: 336-343

12 Kobayashi Y, Bhatt ID. Anti depressant effect of the Atractylodes japonica essential oil in mice. Aroma Res 2005; 6: 40-45 